\title{
COOLING WORKING ROLLS OF THE FINISHING SECTION OF WIDE-STRIP HOT ROLLING MILLS
}

The contribution deals with heat nucleation in rolling on the hot wide strip mill as well as into following transfer to the rolls without friction heat being involved. This work has resulted in the computer program owned by author. It represents the most accessible computer technique and the dependence of the accepted heat amount on the revolutions and angle of bite, as well as the dependence on the temperature of the roll surface which may participate in the initiation and widening of the surface friction coefficient and roll stand sequence.

Key words: cooling working rolls, finishing section, wide strip, hot rolling mills

\section{Introduction}

Due to the stringent demands on the quality of rolled sheets it is necessary to gradually modernise rolling trains. An important role in every rolling mill train is played by the working rolls whose quality also determines the final quality of products, their cost and output of the rolling mill train. The finishing lines of the widestrip rolling mill trains consist of six-seven stands. In the pass, the finishing line used cast iron rolls with a non-specified hardened working layer. The use of these rolls had a number of disadvantages [1], [2]:

- high specific consumption of rolls per unit mass of rolled material;

- reduced hardness of the surface of the body of the roll and associated negative effect on the dimensions and surface quality of the rolled strips.

Because of this it was necessary to find and use rolls of higher quality. The cast iron rolls with the hardened layer were replaced by centrifugally cast rolls with a higher chromium content.

\section{Cooling working rolls}

After introducing the rolls it was necessary to pay special attention to cooling the rolls. This is associated with utilisation of theoretical information on heating and cooling the rolls and practical experience obtained in operation with them. The need to examine this problem is also indicated by the fact that these rolls are subjected to high demands caused by changes in the thermal-physical properties in comparison with the cast iron rolls with a non specified hardened layer.

The surface temperature of the roll is an important quantity in cooling the rolls which influences the deformation of the working rolls, their wear and quality of the surface, as well as dimensions and quality of the surface of rolled strips. According to service experience obtained in rolling mill trains using rolls with a high chromium content, the surface of the roll is not excessively damaged by cracks formed under the effect of heat if the surface temperature of the roll does not exceed $60^{\circ} \mathrm{C}$ in removal from the stand. Regardless of this fact, this temperature cannot be regarded as an absolute value. Concerning continuous welding process the extent of temperature variations decreases and the temperature of the roll increases. As a result of a reduction of the temperature variations, the thermal shock to which the working rolls are subjected decreases. Practical experiences show that temperature variations have far worse consequences for damaging the surface of the roll than the roll temperature.

'The cooling of the rolls is also significantly influenced by the amount and pressure of cooling and the position of collectors. The majority of rolling mill trains use a large number of high-pressure spraying nozzles for cooling the working rolls. These nozzles are installed in the so-called cooling connectors. However, incorrect application of the high-pressure nozzles may limit the cooling effect of water. To obtain the most effective cooling effect, the pressure and the angle of the cooling jet should be selected in such a manner as to avoid reflection of water droplets with a high energy from the surface of the roll. This would reduce the contact time of cooling water with the surface and, consequently, reduce the cooling effect The nozzles distributed in a relatively stable position form different cooling zones on rolls with different diameters because the distance between the nozzles and the cooled surface of the roll changes.

The highest temperature of the working roll is recorded in the area of contact with the strip. In this zone, higher temperatures are found only in a very thin layer. It is therefore essential to ensure that the heat received by the roll from the strip is removed as soon

\footnotetext{
* Peter Horbaj ${ }^{1}$, Jozef Víglaský ${ }^{2}$, Dušan Mikolaj ${ }^{1}$

${ }^{1}$ Faculty of Mechanical Engineering, Technical University in Košice, Vysokoškolská 4, 04200 Košice, Slovak Republic, E-mail: peter.horbaj@tuke.sk, dusan.mikolaj@tuke.sk,

${ }^{2}$ Faculty of Environmental and Manufacturing Technology, Technical University in Zvolen, T. G. Masaryka 24, 96053 Zvolen, Slovak Republic, Email: viglasky@vsld.tuzvo.sk
} 
as possible, i.e., immediately after the completion of contact between the roll and the strip. The heat received by the roll must be removed to avoid its further penetration into the roll. This can be ensured by correct distribution of the cooling collectors. In many cases, even if the pressure conditions are maintained and the amount of cooling water is sufficient, with the correct distribution of collectors, rolls in certain stands of the finishing line can be overheated, i.e. the surface temperature exceeds the allowed value. This results in insufficient cooling which requires detailed analysis of the thermal processes taking place during cooling of the rolls.

In cooling the rolls it is necessary to take into account the fact that the amount of heat received by the roll from the strip must be equal to the amount of removed heat. If this equilibrium is disrupted, i.e., if the amount of removed heat is lower, heat would build up in the roll and, in the final analysis, the roll temperature would increase.

In analysing the amount of heat received from the surface it is necessary to take into account the following heat sources and solutions of the equations, Fig. l:

1. The equation of heat conduction in the roll.

2. The equation in of heat conduction in the strip which takes into account the development of heat caused by plastic deformation.

3. The equation of heat conduction through the oxidation film existing between the roll and the strip-takes into account heat caused by friction.

For different rolling conditions we calculated the transfer of heat to the roll which does not include the friction heat [3]. The basis for compiling the mathematical model of the temperature field of the roll in hot rolling is the differential equation of heat conduction in the roll:

$$
\begin{aligned}
& \frac{\partial^{2} \Theta(\rho, \varphi, F o)}{\partial \rho^{2}}+\frac{1}{\rho} ; \\
& \frac{\partial \Theta(\rho, \varphi, F o)}{\partial \rho}+\frac{1}{\rho^{2}} \cdot \frac{\partial^{2} \Theta(\rho, \varphi, F o)}{\partial \varphi^{2}}=\frac{\partial \Theta}{\partial F_{o}}
\end{aligned}
$$

In solving equation (1) it is necessary to know the initial and boundary conditions:

- initial condition

$$
\Theta=\Theta_{0} \text { for } F o=0
$$

- boundary conditions

$$
\begin{aligned}
& \Theta=\Theta(\varphi) \cdot e^{i . P d . F o} \quad \text { by } \rho=1 \\
& \Theta(\rho, \varphi, F o)=\Theta[\rho,(\varphi+2 k \cdot \pi), F o]+K \cdot \Delta t
\end{aligned}
$$

where exponent $i$ is an argument which expresses the complexity and periodicity of the boundary conditions. The first term on the right hand side of the equation (3) represents the periodicity of the function and the second term the temperature increase on the surface as a result of deformation.

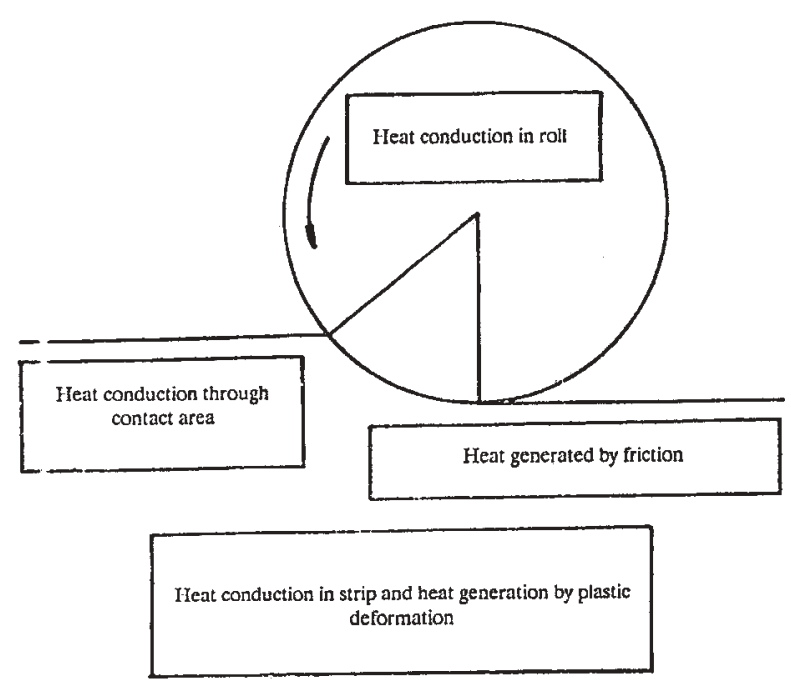

Fig. 1 Heat sources

The constant $K$ can be determined by means of experiments. The value $\Delta t$ expresses the temperature increase during deformation. At $700-1300{ }^{\circ} \mathrm{C}$ the deformation energy is completely transformed to thermal energy. The increase of the energy of the stressed state can be regarded as negligible. The value $\Delta t$ is determined from (4):

$$
\Delta t=\frac{p_{s} \cdot \ln h_{i-1} / h_{i}}{c_{k} \cdot \rho_{k}}
$$

where the values of the mean deformation resistance $p_{s}$ for different stands in the line, for different diameters of the working rolls, for different revolutions of the working rolls and different temperatures can be found in the literature [4].

Figure 2 shows the diagram of distribution of the boundary conditions on the surface of the upper working roll. In the zone of contact between the roll and the rolled strip $\varphi_{1}$ the temperature on the surface of the roll is equal to the strip temperature $t_{p}$. In the cooling zone $\varphi_{3}$ the temperature is determined by the temperature of cooling water $t_{v}$. In the zones $\varphi_{2}$ and $\varphi_{4}$ it can be assumed that the surface is insulated from water with wipers. During rolling the roll rotates at the angular speed $\omega_{0}$ and, consequently the equation (1) must be solved for the rotating system. The differential equation (1) together with the unambiguity conditions (5) and (6) makes it possible to obtain a solution describing the radial non stationary temperature field of the rotating roll.

Fig. 3 shows the distribution of the boundary conditions of the surface of the rotating roll with the angular speed $\omega_{0}$. The vertical axis gives the temperature distribution $\Delta t$ which varies from $t_{o}$ to $t_{p}$. In the zone of angle $\varphi_{2}$ the temperature decreases exponentially. In the zone of angle $\varphi_{3}$ the roll is cooled with water at such a rate that the surface temperature of the roll can be regarded 


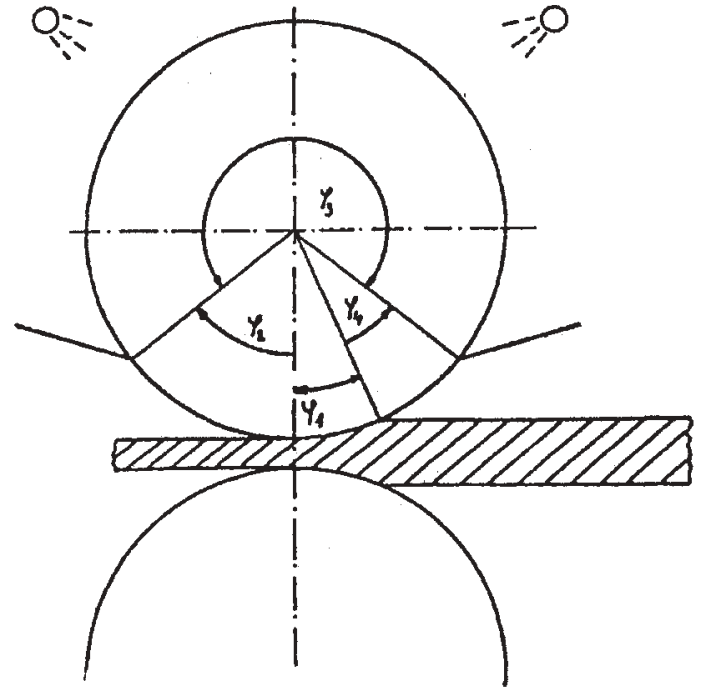

Fig. 2 Distribution of boundary conditions on the surface of the working roll

as equal to the temperature of the cooling water. In the zone $\varphi_{4}$ the temperature of the surface exponentially increases, as in the zone $\varphi_{2}$. As a result of transformation of the equations, the final equation of the amount of heat received in the strip by the two rolls has the form:

$$
Q\left(\varphi_{0}\right)=2 \lambda \cdot b \cdot \sqrt{P d}(t p-\bar{t}) \cdot\left(\varphi_{1}+\frac{\varphi_{2}}{2}\right)
$$

In the quasistationary conditions, the amount of heat supplied to the rolls is equal to the amount of heat taken away during a single revolution:

$$
Q\left(\varphi_{0}\right)=Q\left(\varphi_{m}\right)
$$

The area $S_{1}+S_{2}$ in Fig. 3 corresponds to the supplied heat and $S_{3}+S_{4}$ to the heat removed.

On the basis of the above results we compiled a program for calculating the amount of received heat in different rolling conditions. Fig. 4 and 5 show the dependence of the amount of received heat for the finishing line of the wide-strip hot rolling mill train. The amount of received heat was calculated on the basis of the our programme "Calculation of heating of rolls"[1]. Fig. 4 can be used to compare the amount of received heat for different revolutions in the individual stands. The graph indicates clearly the degree of loading of the individual stands. Fig. 5 shows the dependence of the amount of heat on the angle of engagement. This heat does not yet include the friction heat.

Fig. 6 shows the distribution of the surface temperature of the rolls in relation to the friction heat which is proportional to the rolling speed. An increase of the temperature of the finishing line is caused by the formation of heat as a result of friction due to higher rolling speeds. In higher loading of the mills, $A$ (high rolling speed), the curve increases above the optimum temperature of the surface

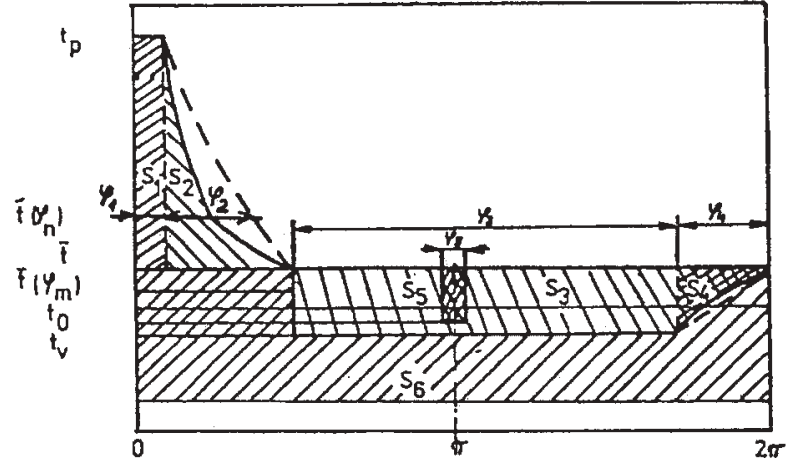

Fig. 3 Distribution of boundary conditions on the circumference of the roll

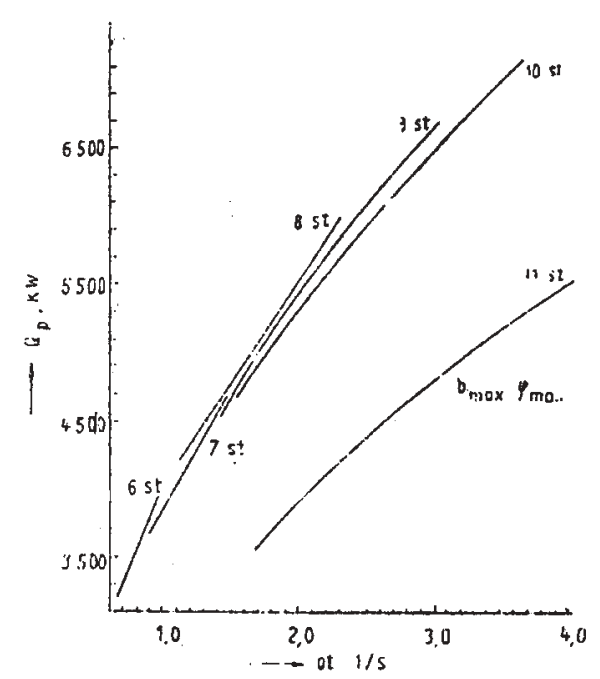

Fig. 4 Dependence of the amount of received heat on revolutions

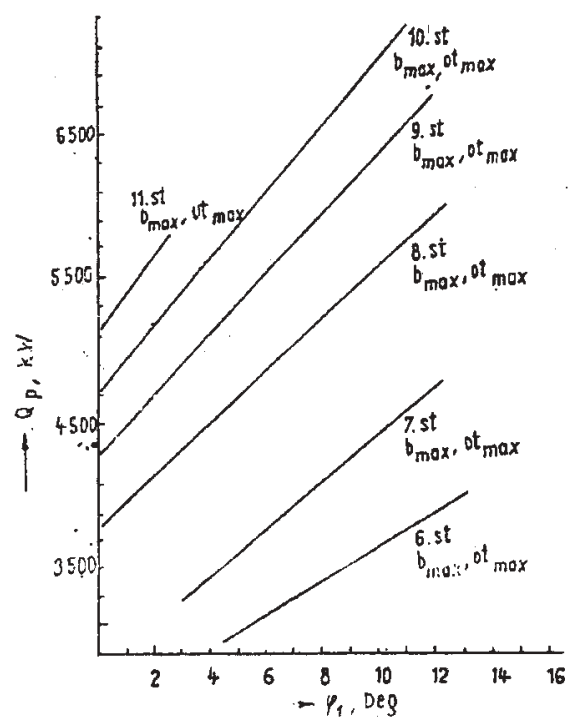

Fig. 5 Dependence of the amount of received heat on the angle of engagement 
of the rolls and the rolls can be subjected to a considerable risk of damage in comparison of the values obtained under the normal rolling conditions, $B$ (normal rolling speed) [5]. The optimum surface temperature of the roll is represented by the value specified by the manufacturer.

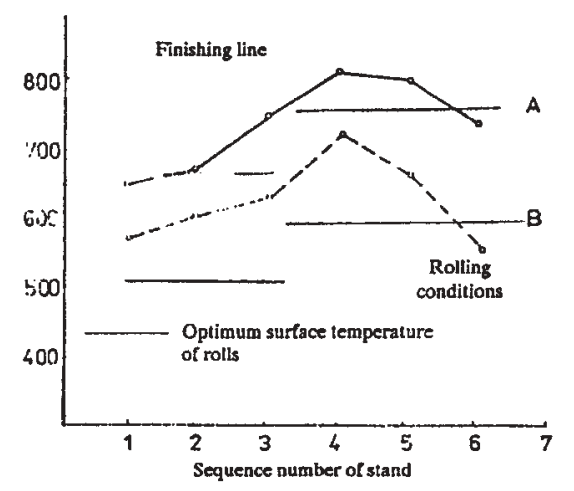

Fig. 6 Dependence of the surface temperature of rolls on the rolling speed in the individual stands of rolling trains

Fig. 7 shows the dependence of the maximum surface temperature of the roll on the friction coefficient at different rolling speeds. As indicated by Fig. 7, the friction coefficient determined from the literature data, for example [6], has strong effect on the surface temperature of the roll.

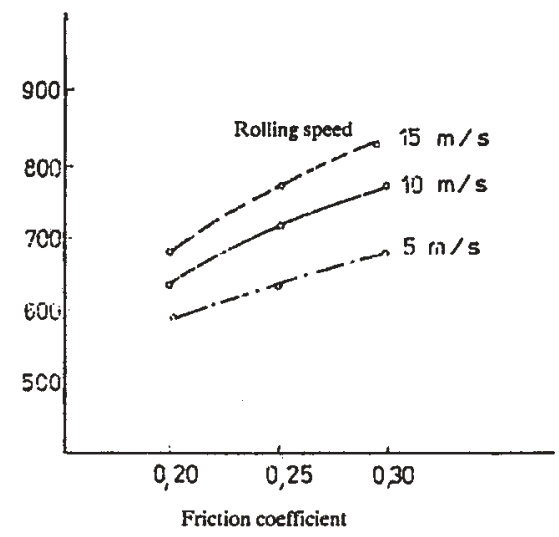

Fig. 7 Dependence of surface temperature on friction coefficient

\section{Conclusion}

The following conclusions can be drawn:

- Special attention must be given to the thermal loading of the individual stands of the finishing lines of the wide - strip hot rolling mills (it is necessary to take into account all heat sources which change in relation to different rolling conditions);

- It is necessary to consider the pressure conditions and the distribution of cooling water supplied to the individual rolls of the finishing line as well as the distribution of water at the inlet and outlet for the individual stands;

- Special attention must be given to the risk of overheating the rolls in service in the rolling conditions in which the individual stands are subjected to the maximum loads. In the future it would be necessary to examine new systems of cooling the rolls in the finishing line, for example, cooling by means of the water wall, or water with a low pressure using collectors with a slit along the entire width. Water is then trapped at a low energy and the water film should remain on the surface curve as long as possible [7] and [8].

In conclusion it can be said that to propose suitable conditions of cooling the individual stands, the calculations must be supplemented by the amount of heat formed under the effect of friction in relation to the rolling speed and the friction coefficient.

After determining this heat it will be necessary to determine accurate conditions of cooling which ensure sufficiently effective cooling of the rolls [10,11, 12, 13].

Symbols:

$\Theta\left(\rho, \varphi, F_{0}\right)$ - relative temperature $\Theta=t-t_{\min } / t_{\max }-t_{\min }$ $t(\rho, \varphi, F o) \quad$ - surface temperature of the roll

$\rho=r / R \quad$ - relative dimensionless radius

$R \quad$ - roll radius, $0 \leq \rho \leq 1$

$F_{0}=a \cdot \tau / R^{2}-$ Fourier criterion

$P d=\omega_{0} \cdot R^{2} / a \quad$ - Predvoditelev's criterion

a $\quad$ - heat conductivity coefficient, $\mathrm{m}^{2} \cdot \mathrm{s}^{-1}$

$b \quad$ - the width of rolled strip, $\mathrm{m}$

$c_{k} \quad-$ specific heat capacity of the material, $\mathrm{kJ} \cdot \mathrm{kg}^{-1} \cdot \mathrm{K}^{-1}$

$h \quad-$ the thickness of the rolled strip, $m$

$h_{i} \quad-\quad$ the thickness of the rolled strip after $i$-th pass, $\mathrm{m}$

$h_{i-1} \quad-$ the thickness of the rolled strip after $i-1$-th pass, $m$

$p_{s} \quad$ - mean deformation resistance, $\mathrm{Pa}$

$t_{P} \quad$ - strip temperature, ${ }^{\circ} \mathrm{C}$

$t \quad$ - mean temperature in the range $\varphi_{m}=\varphi_{3}+\varphi_{4},{ }^{\circ} \mathrm{C}$

$\Delta t \quad-$ temperature increase in deformation, ${ }^{\circ} \mathrm{C}$

$\lambda \quad-$ heat conductivity coefficient, $\mathrm{W} \cdot \mathrm{m}^{-1} \cdot \mathrm{K}^{-1}$

$\rho_{k} \quad-$ density of material, kg.m ${ }^{-3}$

$\tau \quad-$ time, s

$\omega \quad-$ angular speed, $\mathrm{s}^{-1}$

\section{Acknowledgements}

This research has been sponsored by the grant from the Scientific Grant Agency of Ministry of Education of the SR and Slovak Academy of Sciences, under the contracts No. 1/1105/04 VEGA "Research effect of composition of biogas, sludge gas and landfill gas on operating characteristics of a cogeneration unit", as well as Dutch-Slovak project PSO 98/SK/2/16 "Replacement of brown coal fired boilers by a biomass-fired boiler at the School Forest Enterprise of TU in Zvolen".

The authors are greatly indebted to the mentioned institutions for sponsoring this research work. 


\section{Reference}

[1] ČIŽMÁR, J., HORBAJ, P.: Cooling working rolls of the finishing section of wide-strip hot rolling mills (in Slovak), Hutnícke listy, 54/1990, No. 9, pp. 639-644

[2] NOVÁK, J., PAVLENKO, S.: Automation of pipeline energetics systems component manufacturing. In: Automation 2001, Warszawa, Poland, March 2001, pp. 75-82

[3] SHICKOV, A. N.: Temperature conditions in sheet rolling rolls (in Russian), Verlag Leningrad University, Leningrad, 1974

[4] RAUDENSKÝ, M.: Simulation of thermal processes in products of hot rolling (in Czech), Hutnícke listy, 52/1988, No. 9, pp. 623-626

[5] OSAMU, K. et. al.: Relation between Calculated Surface Temperature and Deteration of Hot Strip Work Rolls, Transaction of the Iron and Steel Institute of Japan, No. 12, 1980

[6] Cooling Water Volume of Hot Strip Mill Finishing Stands. Report on Hot Strip Mills in the USSR and other industrial countries, VSŽ a.s., Steelworks, Košice, 1987

[7] ANDREJČÁK, I., MOLNÁR, V.: Technology of pressurized casting (in Slovak), ES FVT Prešov, pp. 71, ISBN 80-7099-419-3

[8] KIZEK, J., LAZIČ, L.: Simulation method for optimization of a mixture of fuel gases. Metalurgija, 38/1999, No. 2, pp. 109-113

[9] VÍGLASKÝ, J.: Technical-economic evaluations of solar air collector application at a sawn timber kiln (in Slovak), TU Zvolen, Report No. 02-522-804/3, 1989, p. 53.

[10] RUŽINSKÁ, E.: The modificated Black Liquors for Preparation of perspective Wood-based Composite Materials. Proceedings from 7th International Scientific Conference „CO-MAT-TECH". STU MTF in Trnava, 1999, pp. 170-175.

[11] RUŽINSKÁ,E.: A Perspective Wood-based Composite Materials. Part I.: Study of Preparation and Evaluation of Selected Properties of Adhesive Mixtures. Proceeding from 4th International Scientific Conference „Wood and Fire Safety". Štrpské Pleso - Patria, 2000, pp. 297-304.

[12] RUŽINSKÁ, E.: Effective Utilization of Kraft Black Liquors for Wood-based Composite Materials. Proceedings from 13th International Conference "Pulp \& Paper 2002". Brno, 2002, CD, 6 p.

[13] RUŽINSKÁ, E.: Thermal characteristics of Modified Kraft Black Liquors and Sulphate Lignins. Part I. Thermogravimetry (TG, DTG). Proceedings from international conference "Fire Engineering 2002". Lučenec, Hotel Reduta, 2002, pp. 337-340. 